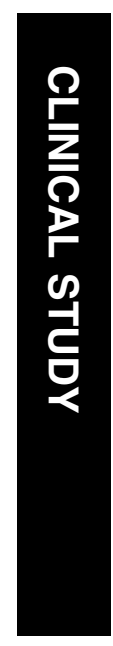

\title{
Evaluation of arteriovenous crossing sheathotomy for decompression of branch retinal vein occlusion
}

${ }^{1}$ Department of Ophthalmology, Uludag University School of Medicine, Bursa, Turkey

${ }^{2}$ Department of Ophthalmology, Kocatepe University School of Medicine, Afyon, Turkey

Correspondence: R Avci, Uludağ Üniversitesi Tıp Fakültesi Göz Hastalıkları Anabilim Dalı, Vitreo-Retinal Cerrahi Birimi, Görükle, Bursa 16059, Turkey. Tel: + 90224 4428071; Fax: + 902244428070 E-mail: ravci@ uludag.edu.tr or ÜÜ Ínan E-mail: uinan@ aku.edu.tr

Received: 15 March 2006; Accepted in revised form: 8 August 2006

Published online:

27 October 2006

None of the authors has any proprietary interest in any matter mentioned in this study

Presented at the meeting of the Turkish

Ophthalmological Society, Antalya, September 2005.
Abstract

Purpose To report the effects of arteriovenous adventitial sheathotomy on anatomical and functional improvements in patients with macular oedema due to branch retinal vein occlusion (BRVO).

Methods Pars plana vitrectomy and arteriovenous sheathotomy was performed on 11 patients with BRVO who had vision loss due to macular oedema. Ten patients with macular oedema due to BRVO and who have been treated with grid laser photocoagulation were included in the control group. The measurement of visual acuity with ETDRS chart was taken preoperatively and at 1, 3, 6, and 9 months follow-up in the study group and at 1, 3, 6, and 9 months after grid laser in the control group.

Results The mean preoperative logMAR visual acuity was $0.84 \pm 0.3$ in the surgical group and $1.06 \pm 0.4$ in the control group. The postoperative mean $\operatorname{logMAR}$ visual acuity was $0.41 \pm 0.2,0.40 \pm 0.2,0.40 \pm 0.3$, and $0.36 \pm 0.3$ at $1,3,6$, and 9 months follow-up, respectively. In the control group the postlaser mean $\log$ MAR visual acuity was $0.92 \pm 0.3$, $0.87 \pm 0.4,0.85 \pm 0.3$, and $0.82 \pm 0.3$ at $1,3,6$, and 9 months follow-up, respectively. The improvements of visual acuity in both groups were statistically significant when compared to pretreatment $(P=0.003$ and $P=0.007$ at 9 months in the study and control group, respectively).

Conclusion Arteriovenous sheathotomy for decompression of BRVO in patients who have vision loss due to macular oedema was safe and effective for anatomical and functional improvement and resulted in significantly better visual outcomes than a matched control group of laser-treated eyes.

Eye (2008) 22, 120-127; doi:10.1038/sj.eye.6702633; published online 27 October 2006

Keywords: sheathotomy; macular oedema; branch retinal vein occlusion

Introduction

After diabetic retinopathy, branch retinal vein occlusion (BRVO) is the second most commonly occurring vascular disorder of the retina.

Patients who have developed BRVO may suffer from severe vision loss due to retinal haemorrhages, macular oedema, or ischaemia. The site of occlusion in BRVO has been found to be the arteriovenous crossing level where arteriole and vein share a common adventitial sheath. ${ }^{1,2}$ In the past, several reports have confirmed the hypothesis that the arteriovenous crossing site is a causative factor in vein occlusion..$^{3-7}$ It has been established that at the arteriovenous crossing site, the arteriole lies over the vein in $97-99 \%$ of patients with BRVO while it only lies over it in 55-70\% of normal subjects. ${ }^{7}$ As the majority of patients with BRVO have systemic arterial hypertension, the arteriole at the crossing site has hypertrophy of the medial layer of its wall and wall thickening, which results in compression of the underlying venule. A thickening in the common adventitial sheath that secures the arteriole to the venule contributes to this mechanical compression. It is believed that compression of the vein at the arteriovenous crossing site causes venous lumen changes and endothelial damage which 
in turns lead to turbulence in the venous outflow. Turbulence with stasis is well known to predispose to thrombus formation at the site of endothelial damage. The end result is vein occlusion. Thus an incision in the common adventitial sheath may relieve compression at the crossing site. It has been hypothesized that surgical decompression or separation of the arteriole from the venule by sheathotomy would allow acceleration of the recanalization of the venous flow and reperfusion of the retina. Arteriovenous crossing sheathotomy has been described as a novel approach to management of patients with BRVO, aiming to alleviate compression and restore venous drainage. ${ }^{8}$ Several authors have attempted to perform adventitial sheathotomy to manage macular oedema due to BRVO. ${ }^{8-16}$

In our study, we analysed our results in patients who were treated with arteriovenous adventitial sheathotomy for the treatment of macular oedema associated with BRVO.

\section{Methods}

Patients presented with BRVO accompanied by macular oedema and visual acuity equal to or less than 20/40 were considered for the study. Patients were informed about the natural course of the disease and various treatment modalities including conventional laser treatment and arteriovenous crossing sheathotomy. The experimental nature of arteriovenous sheathotomy procedure and current literature results, as well as the results of conventional laser treatment were fully explained to each patient. The study included 21 eyes of 21 patients with BRVO. Eleven eyes of 11 patients who agreed to undergo arteriovenous sheathotomy and signed an informed consent form underwent arteriovenous crossing sheathotomy operation (Group I). All patients were operated on by the same surgeon (RA) between June 2002 and March 2004. The patients were seven males and four females with an average age of $58.2 \pm 10.7$ years (range $44-73$ years). Nine patients had previously established systemic hypertension. Extensive macular haemorrhages and oedema were present in all patients. The time from the onset of visual loss to surgery ranged from 3 to 22 weeks with a mean of $14.0 \pm 6.5$ weeks. Table 1 outlines the clinical characteristics of the study population.

Ten patients who were diagnosed as BRVO between December 2002 and April 2004 and who did not agree to undergo arteriovenous sheathotomy were included in the control group. The control patients consisted of six males and four females with an age range of 54-77 years (mean $65.0 \pm 6.6$ years). Eight patients had previously established hypertension while one patient was diagnosed hypertensive after presentation. The duration of symptoms varied between 5 and 24 weeks (mean $14.2 \pm 5.5$ weeks). The patients in the control groups were treated with thermal laser photocoagulation 3-7 months after presentation (mean 2.3 times per patient). Followup examinations and visual acuity measurements with ETDRS chart were performed at 1, 3, 6, and 9 months then at 6-month intervals thereafter.

Inclusion criteria were the same for both groups: presentation within 1 year of the onset of symptoms, best-corrected ETDRS visual acuity equal to or worse than 20/40 and macular oedema involving the fovea. Any eyes that had retina or iris neovascularization were excluded from the study. Patients with diabetic retinopathy or any other disease that could cause vision loss were not included in the study. Total blood cell count, protein electrophoresis, total cholesterol, HDL and LDL cholesterol, triglyceride, urea and creatinine, fasting blood glucose level, $\mathrm{HbA1c}$, erythrocyte sedimentation rate, protein $\mathrm{C}$ and $\mathrm{S}$, fibrinogen, $\mathrm{PT}$, APTT, coagulation times, and lupus anticoagulant were investigated in all patients. There was no any abnormality in none of these parameters in neither group. Any patient with BRVO

Table 1 Demographics and visual results in both groups

\begin{tabular}{lccc}
\hline & The surgical group & The control group & P-value \\
\hline Age & $58.2 \pm 10.7(44-73$ years $)$ & $65.0 \pm 6.6(54-77$ years $)$ & 0.19 \\
Body mass index & $26.2 \pm 2.5(20.2-30.4)$ & $27.6 \pm 1.5(25.7-30.5)$ & 0.13 \\
Mean preop VA LogMAR & $0.84 \pm 0.3$ & $1.06 \pm 0.4$ & - \\
Mean BRVO duration & $14.0 \pm 6.5(3-22$ weeks) & & - \\
VA changes & & 2 & - \\
Increase as $\geq 4$ lines $(n)$ & 11 & 1 & - \\
Increase as $\geq 2$ lines $(n)$ & 0 & 3 & - \\
No changes $(n)$ & 6 & $1.4 \pm 1.3$ lines & - \\
VA $>20 / 40(n)$ & $4.3 \pm 2.2$ lines & $2.4 \pm 1.8$ lines & 0.002 \\
Mean increase in VA at 3 mo & $4.8 \pm 1.4$ lines & $5(\% 50)$ & 0.002 \\
Mean increase in VA at 9 mo & 9 (\%82) & & \\
Oedema resolution $(n)$ & & & \\
\hline
\end{tabular}

VA: visual acuity, BRVO: branch retinal vein occlusion. 
who was determined to have any abnormality was not included in the study. Six patients in the study group and five patients in the control group were chronic smokers. Length and weight were recorded for all patients and body mass index was calculated in both groups (Table 1).

Best-corrected visual acuity was checked before surgery and throughout the follow-up period. Using the ETDRS chart, visual acuity was measured by masked observers who received no information on the procedures which were performed. Colour fundus photographs were taken and fluorescein angiography was performed preoperatively then at $1,3,6$, and 9 months and then 6-month intervals thereafter. The results of the study in the both groups were retrospectively analysed.

A standard three port pars plana vitrectomy was performed. After the removal of the posterior hyaloid which was attached in $11 / 11$ eyes $(100 \%)$, the dissection of the adventitial sheath at the site of arteriovenous crossing where occlusion had occurred was performed parallel to the arteria using a 23 gauge microvitreoretinal blade bent at the tip. A membrane pick was then introduced and moved between both vessels, and the completion of the arteriovenous dissection was proven by a gentle lifting of the overcrossing artery. No internal limiting membrane in the macular area or the arteriovenous crossing site was removed from any eye.

For data analysis, the Mann-Whitney test, Wilcoxon signed ranks test and Fisher exact test were used. A $P$-value at $<0.05$ was considered as statistically significant.

\section{Results}

Arteriovenous dissection could have been accomplished successfully in all eyes with careful manipulation under high magnification of the operating microscope. No serious intraoperative complication occurred except mild haemorrhage at the site of manipulation in two eyes. This was brought under control by gentle compression. No vitreous haemorrhage was seen in any eye, neither did any retinal tear or detachment develop either during or after surgery. A mild gliozis around the operation site was seen in one eye at the 3-month postoperative visit. Although successful decompression of the arteriovenous crossing was achieved, no changes in the vein diameter or blood flow were detected during the procedure except in two cases where an immediate restoration of downstream blood flow was noticed intraoperatively.

At the 9-month follow-up macular oedema showed resolution in $9 / 11(82 \%)$, persisted in $2 / 11(18 \%)$ in the surgical group and oedema showed resolution in 5/10 $(50 \%)$, persisted in $4 / 10(40 \%)$ and had worsened in $1 / 10(10 \%)$ in the laser-treated group. All eyes in the

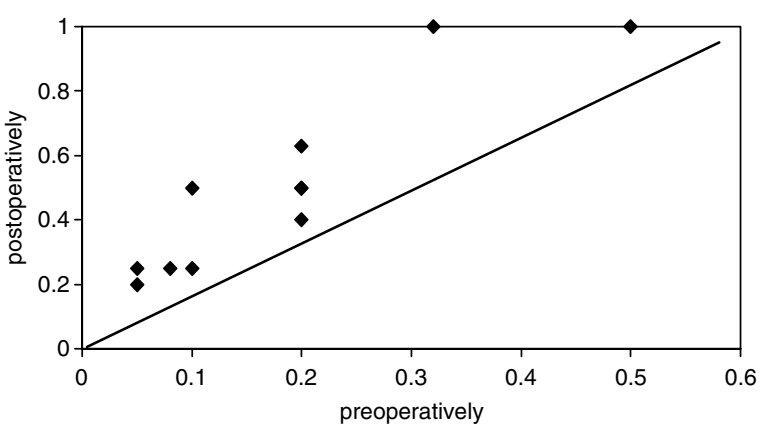

Figure 1 Preoperative and postoperative ETDRS decimal visual acuities.

surgical group showed two lines or more visual acuity improvement (Figure 1), whereas eight eyes in the control group showed two lines or more visual acuity improvement with ETDRS chart (Figure 2). In the control group one patient retained pretreatment vision, while the others gained one or more lines visual acuity with ETDRS chart. Visual acuity improved four lines or more in eight eyes of 11 in the surgical group compared to two eyes of 10 in the control group. The mean visual improvement was $4.8 \pm 1.4$ lines in ETDRS acuity, with a mean preoperative visual acuity of $0.84 \pm 0.3$ (LogMAR) and a mean postoperative LogMAR visual acuity of $0.36 \pm 0.3$ at 9 months in the surgical group $(P=0.003)$. Six patients had $20 / 40$ or better visual acuity at the final follow-up. In the control group, the mean visual improvement was $2.4 \pm 1.8$ lines in ETDRS chart, with a mean prelaser treatment LogMAR visual acuity of $1.06 \pm 0.4$ and mean postlaser LogMAR visual acuity of $0.82 \pm 0.3$ at 9 months visit. Visual improvement was also statistically significant $(P=0.007)$. Three patients had $20 / 40$ or better visual acuity at the final follow-up (Table 1). Visual acuity improvement was better in the study group than in the control group $(P=0.002)$. Retinal haemorrhages had been absorbed completely in both groups at the final follow-up (Figures 3 and 4).

\section{Discussion}

BRVO is the second most common retinal vascular disease affecting $1.6 \%$ of the population over the age of 40 years. ${ }^{1,2}$ Several medical and surgical strategies have been undertaken to manage BRVO. The only therapy of documented benefit for BRVO is retinal thermal laser photocoagulation. Laser photocoagulation has been proved to improve the visual prognosis in patients who develop secondary complications of BRVO such as persistent macular oedema and neovascularization. The comparison of the natural history of macular oedema shows that laser treatment increases the probability of visual improvement with 1.33 lines gain vs 0.2 lines gain 
in the observation alone group. Although the mean visual acuity in laser-treated eyes improved in the Branch Vein Occlusion Study, the treatment effect was negligible when the initial vision was in the poor range of inclusion criteria (20/40-20/200). ${ }^{17-20}$ Thus, a need has arisen for other surgical techniques like surgical vein decompression at the arteriovenous crossing in an attempt to achieve better visual results.

This study showed that patients with vision loss due to macular oedema associated with BRVO have benefited from the operation of pars plana vitrectomy with arteriovenous crossing sheathotomy. The idea of

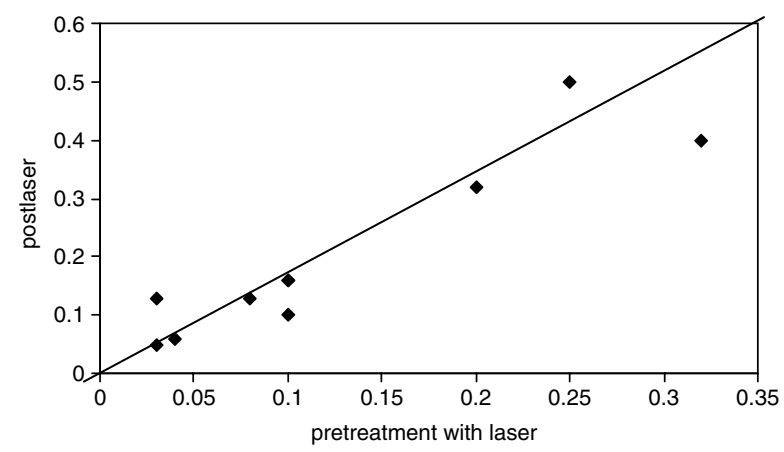

Figure 2 ETDRS decimal visual acuities pretreatment and posttreatment with laser photocoagulation. performing arteriovenous sheathotomy in patients with BRVO originated from the knowledge of pathogenesis of BRVO. It has been shown that BRVO usually occurs at arteriovenous crossings where both vessels share a common thickened and glial sheath. It has been suggested that venous endothelial changes such as damage, alteration, or hyperplasia occur at the arteriovenous crossing itself and this predisposes to BRVO. The venous lumen may be diminished by as much as a third of its baseline diameter at the crossing site. Compounding factors like arteriosclerosis may cause further narrowing. Blood that passes through a focal narrowing of a vessel experiences a flow separation downstream, generating eddies, and a high chance of turbulence. This results in injury to the vascular endothelium, and secondary thrombotic occlusion. ${ }^{1-7}$ Dissection of the adventitial sheath of the arteriovenous crossing to eliminate the primary cause of BRVO was performed in one patient by Osterloh and Charles in 1988. ${ }^{8}$ Eleven years later, Opremcak and Bruce ${ }^{9}$ reported favourable results with sheathotomy in 15 eyes with BRVO. Shah et al ${ }^{10}$ reported a significant improvement of visual acuity in four out of five eyes after sheathotomy for macular oedema due to BRVO.

Although a series of sheathotomy procedures were subsequently reported following the study by Opremcak
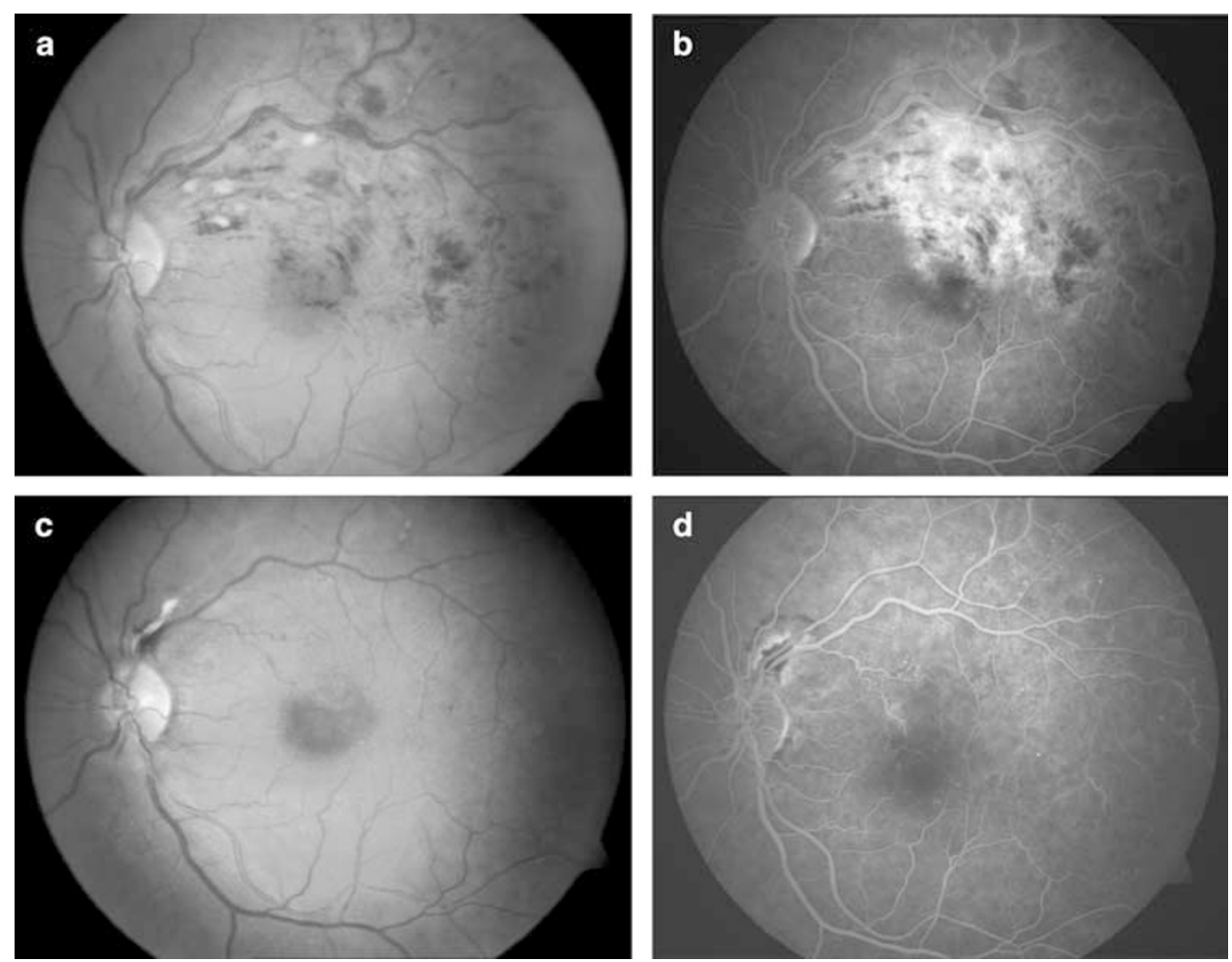

Figure 3 Study group. (a, b) Preoperative fundus photograph and fundus fluorescein angiography in a patient undergoing arteriovenous crossing sheathotomy. LogMAR visual acuity was 0.5 with ETDRS chart. (c, d) Postoperative fundus photograph and fundus fluorescein angiography 6 months after sheathotomy, LogMAR visual acuity was 0.0 with ETDRS chart. 

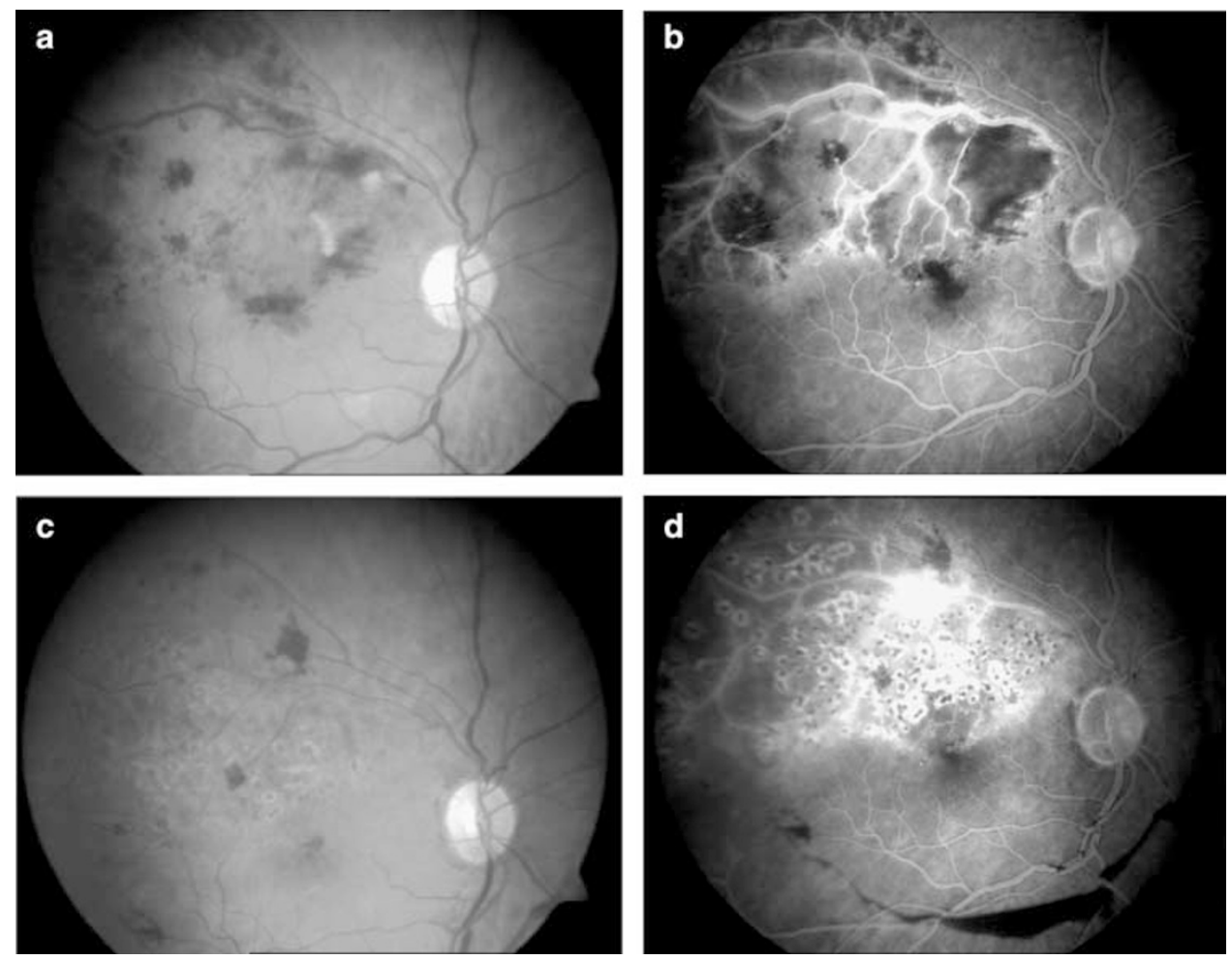

Figure 4 Control group. (a, b) Before the laser treatment. LogMAR visual acuity was 0.6 with ETDRS chart. (c, d) After 6 months after the laser photocoagulation. LogMAR visual acuity was 0.2 with ETDRS chart.

and Bruce, ${ }^{9}$ it has never become widespread routine practice among vitreo-retinal surgeons. One of the reasons for this is that the procedure can be considered technically somewhat difficult to perform and there is the possibility of serious intraoperative complications developing. The surgical outcome that might be obtained after such a complication may be worse than the natural course of the disease. The separation of the arteriole and venule at the arteriovenous crossing site may be difficult enough apart from any added complications such as haemorrhage, tear, and detachment etc. This has been expressed by authors reporting results of sheathotomy. ${ }^{8-16}$ The possibility of rupture of one of the vessels may be frightening and dissuasive for surgeons. What should be known is whether this new surgical procedure is worth performing.

An identical consideration about arteriovenous adventitial sheathotomy is related to the results of studies published in literature to date. To analyse and compare the studies on sheathotomy is difficult because of differences and variations of methodology. ${ }^{8-16,21-30} \mathrm{No}$ control group that has similar conditions could have been created in the majority of the reported studies. Some case reports have shown favourable results while others have not. Like the case series, clinical studies that have been designed prospectively or retrospectively have failed to present consistent conclusions too. Nevertheless, it is possible to make some comment about these contradictory results of adventitial sheathotomy procedure. When a new invasive procedure for a clinical entity is developed it is given some weight if there is clinical improvement, but the real value can only be appreciated by comparing it to the natural course of the disease or the traditional treatment. For this reason, in our study we also reported the natural course of the disease following traditional treatment of laser photocoagulation in our patients in the control group. However, it would be worth scrutinizing the factors affecting arteriovenous adventitial sheathotomy.

Some authors have emphasized the importance of posterior vitreous detachment in eyes with BRVO undergoing sheathotomy operation. ${ }^{21-23}$ They said that the essential part was the development of posterior vitreous detachment. The attached hyaloid may compress a susceptible arteriovenous crossing, resulting in BRVO formation. Among patients with BRVO, the presence of a posterior vitreous detachment is associated with a significantly reduced risk of developing retinal neovascularization, vitreous haemorrhage, and macular oedema. ${ }^{31}$ It has been suggested that the posterior vitreous cortex is implicated in the pathogenesis of the retinal oedema. The results of sheathotomy in eyes with 
posterior vitreous detachment developed previously were not as good as those of the eyes without posterior vitreous detachment before surgery. ${ }^{21}$ Nonetheless, the existence or absence of posterior vitreous detachment was not a criterion; no posterior vitreous detachment was encountered and posterior vitreous cortex was separated intraoperatively in our study.

The studies giving promising results have generally reported the outcomes of case series without a control group. How that control group should be methodologically created is a subject for question. If the study groups are compared with the natural course reported by the BRVO study group, then the case report series seem to give favourable results. As is performed in our study, if patients with BRVO who are only treated with laser photocoagulation are compared to patients who undergo sheathotomy, the results of the surgical choice seem to be superior. Another probable control group may be case series consisting of patients undergoing pars plana vitrectomy without sheathotomy. It has been suggested that the factor having the main effect on sheathotomy procedures is the removal of the vitreous body. A proposed mechanism for the role of the vitreous in the development of complications of retinal vein occlusion includes angiogenic factors released from ischaemic retinal areas transported via the vitreous body. ${ }^{32}$ Traction through vitreous fibres to the Muller cells of the macula may predispose this area to the development of oedema as well. ${ }^{22,33}$ Pars plana vitrectomy has been found to be successful in the resolution of diabetic macular oedema or macular oedema due to venous occlusions. ${ }^{34-37}$ If so, pars plana vitrectomy without sheathotomy may be a better control for sheathotomy procedures. From this perspective our case series could also be criticized. Some authors have performed vitrectomy and internal limiting membrane peeling in addition to sheathotomy for the resolution of macular oedema due to BRVO. ${ }^{24,25}$ The peeling of the internal limiting membrane was not performed in our study and the additional benefit of this manipulation warrants further studies.

However, one point making the interpretation of results of previously reported studies more complicated is that there are some studies reporting that arteriovenous crossing sheathotomy without vitrectomy is effective in the resolution of macular oedema due to BRVO. If vitrectomy alone was an effective element in sheathotomy operations, sheathotomy without vitrectomy would not be successful. Lakhanpal et al ${ }^{26}$ performed 25-gauge transvitreal arteriovenous crossing manipulation without vitrectomy by using a specifically designed blunt 25-gauge flexible-extendable nitinol retinal pick and reported favourable results and clinical improvement with restoration of blood flow by intraoperative re-establishment of a red column of erythrocytes through the previously closed vessel. Fuji et $a l^{27}$ also reported increased visual acuity, improved central foveal thickness and fixation stability on the first day following sheathotomy using a 25-gauge sutureless transconjunctival vitrectomy system without vitrectomy.

When considering the fact that the aim of arteriovenous crossing sheathotomy procedures is to relieve the compression and to re-establish venous perfusion, how this aim was attained with the procedure should be questionable. In spite of the success of vein decompression in most of the operated eyes, a few have had reperfusion. In some of the studies, immediate restoration of downstream blood flow was observed intraoperatively but not observed in others. Restoration of blood flow was not observed in our case series except in two cases. In studies where this issue was investigated an improvement in delay in venular perfusion was reported. Yamaji et a ${ }^{28}$ quantitatively evaluated venular perfusion by fluorescein videoangiography which was performed with a scanning laser ophthalmoscope within 3 days before surgery and within 7 days after surgery. The time difference between the circulation time at the point on the affected venule and that at the point on the normal venule, which represents the filling delay at the venule distal to the arteriovenous crossing site, was compared before and after the sheathotomy operation. The circulation time decreased from $1.36 \pm 1.15 \mathrm{~s}$ preoperatively to $0.72 \pm 0.77 \mathrm{~s}$ postoperatively. Horio and Horiguchi, ${ }^{29}$ evaluated the effect of sheathotomy on retinal blood flow in 7 eyes with BRVO. At 1 week postoperatively, blood flow in the affected vessels had significantly improved from $14.1 \pm 5.7$ to

$27.3 \pm 11.3 \mathrm{pixel}^{2} / \mathrm{s}$. However, the retinal blood flow had reduced at 1-month postoperatively, but foveal thickness gradually decreased over 6 months. Kube et al, ${ }^{30}$ demonstrated that sheathotomy for decompression of BRVO leads to long-term, measurable, and significant decrease of arteriovenous passage time thus indicating at least a partial restoration of normal retinal perfusion in the affected branch. Again, the fields of retinal nonperfusion have been shown to be perfused after sheathotomy in eyes with BRVO. ${ }^{9}$

In the light of the results of our series and the literature, surgery seems to be beneficial for patients with BRVO when compared to patients followed with observation or treated with laser photocoagulation and/ or haemodilution. The question is whether manipulation for arteriovenous crossing is necessary after vitrectomy has been performed. There are still some questions remaining related to the procedure for arteriovenous sheathotomy. There is a need for multicentre trials to answer these questions. There are cases in which the procedure was unsuccessful as well as successful cases. 
Thus, the important point is to establish which factors determine the success of the surgery. The effect of the duration of BRVO, timing of surgery, patient's age, existence of posterior vitreous detachment, extent of areas of capillary nonperfusion, massive haemorrhage, location of arteriovenous crossing site, macular ischaemia, surgical technique, or experience of surgeon and other possible factors should be determined. After determination of these factors, arteriovenous crossing sheathotomy can be undertaken in patients where success is anticipated.

\section{References}

1 Scott IU. Vitreoretinal surgery for complications of branch retinal vein occlusion. Curr Opin Ophthalmol 2002; 13: 161166

2 Shah GK. Adventitial sheathotomy for treatment of macular edema associated with branch retinal vein occlusion. Curr Opin Ophthalmol 2000; 11: 171-174.

3 Christoffersen NLB, Larsen M. Pathophysiology and hemodynamics of branch retinal vein occlusion. Ophthalmology 1999; 106: 2054-2062.

4 Kumar B, Yu DY, Morgan WH, Barry CJ, Constable IJ, McAllister IL. The distribution of angioarchitectural changes within the vicinity of the arteriovenous crossing in branch retinal vein occlusion. Ophthalmology 1998; 105: 424427.

5 Staurenghi G, Lonati Ch, Aschero M, Orzalesi N. Arteriovenous crossing as a risk factor in branch retinal vein occlusion. Am J Ophthalmol 1994; 117: 211-213.

6 Mitchell P, Smith W, Chang A. Prevalence and association of vein occlusion in Australia. The Blue Mountains Eye Study. Arch Ophthalmol 1996; 114: 1243-1247.

7 Duker JS, Brown GC. Anterior location of the crossing artery in branch retinal vein occlusion. Arch Ophthalmol 1989; 107: 998-1000.

8 Osterloh MD, Charles S. Surgical decompression of branch retinal vein occlusion. Arch Ophthalmol 1988; 106: 1469-1471.

9 Opremcak EM, Bruce RA. Surgical decompression of branch retinal vein occlusion via arteriovenous crossing sheathotomy: a prospective review of 15 cases. Retina 1999; 19: $1-5$.

10 Shah GK, Sharma S, Fineman MS, Federman J, Brown MM, Brown GC. Arteriovenous adventitial sheathotomy for the treatment of macular edema associated with branch retinal vein occlusion. Am J Ophthalmol 2000; 129: 104-106.

11 Garcia-Arumi J, Martinez-Castillo V, Boixadera A, Blasco H, Corcostegui B. Management of macular edema in branch retinal vein occlusion with sheathotomy and recombinant tissue plasminogen activator. Retina 2004; 24: 530-540.

12 Mason III J, Feist R, White Jr M, Swanner J, McGwin Jr G, Emond T. Sheathotomy to decompress branch retinal vein occlusion: a matched control study. Ophthalmology 2004; 111: 540-545.

13 Han DP, Bennett SR, Williams DF, Dev S. Arteriovenous crossing dissection without separation of the retina vessels for treatment of branch retinal vein occlusion. Retina 2003; 23: $145-151$.

14 Le Rouic JF, Bejjani RA, Rumen F, Caudron C, Bettembourg $\mathrm{O}$, Renard G et al. Adventitial sheathotomy for decompression of recent onset branch retinal vein occlusion. Graefes Arch Clin Exp Ophthalmol 2001; 239: 747-751.

15 Cahill MT, Fekrat S. Arteriovenous sheathotomy for branch retinal vein occlusion. Ophthalmol Clin North Am 2002; 15: 417-423.

16 Cahill MT, Kaiser PK, Sears JE, Fekrat S. The effect of arteriovenous sheathotomy on cystoid macular oedema secondary to branch retinal vein occlusion. $\mathrm{Br} J$ Ophthalmol 2003; 87: 1329-1332.

17 The Branch Vein Occlusion Study Group. Argon laser photocoagulation for macular edema in branch retinal vein occlusion. Arch Ophthalmol 1984; 98: 271-282.

18 Branch Vein Occlusion Study Group. Argon laser scatter photocoagulation for prevention of neovascularization and vitreous hemorrhage in branch vein occlusion. A randomized clinical trial. Arch Ophthalmol 1986; 104: 34-41.

19 Esrick E, Subramanian ML, Heier JS, Devaiah AK, Topping TM, Frederick AR et al. Multiple laser treatments for macular edema attributable to branch retinal vein occlusion. Am J Ophthalmol 2005; 139: 653-657.

20 Arnarsson A, Stefansson E. Laser treatment and the mechanism of edema reduction in branch retinal vein occlusion. Invest Ophthalmol Vis Sci 2000; 41: 877-879.

21 Charbonnel J, Glacet-Bernard A, Korobelnik JF, NyoumaMoune E, Pournaras CJ, Colin J et al. Management of branch retinal vein occlusion with vitrectomy and arteriovenous adventitial sheathotomy, the possible role of surgical posterior vitreous detachment. Graefes Arch Clin Exp Ophthalmol 2004; 242: 223-228.

22 Yamamoto S, Saito W, Yagi F, Takeuchi S, Sato E, Mizunoya $\mathrm{S}$. Vitrectomy with or without arteriovenous adventitial sheathotomy for macular edema associated with branch retinal vein occlusion. Am J Ophthalmol 2004; 138: 907-914.

23 Figueroa MS, Torres R, Alvarez MT. Comparative study of vitrectomy with and without vein decompression for branch retinal vein occlusion: a pilot study. Eur J Ophthalmol 2004; 14: 40-47.

24 Mester U, Dillinger P. Vitrectomy with arteriovenous decompression and internal limiting membrane dissection in branch retinal vein occlusion. Retina 2002; 22: 740-746.

25 Mester U, Dillinger P. Treatment of retinal vein occlusion. Vitrectomy with arteriovenous decompression and dissection of the internal limiting membrane. Ophthalmology 2001; 98: 1104-1109.

26 Lakhanpal RR, Javaheri M, Ruiz-Garcia H, de Juan E, Humayun MS. Transvitreal limited arteriovenous-crossing manipulation without vitrectomy for complicated branch retinal vein occlusion using 25-gauge instrumentation. Retina 2005; 25: 272-280.

27 Fujii GY, de Juan Jr E, Humayun MS. Improvements after sheathotomy for branch retinal vein occlusion documented by optical coherence tomography and scanning laser ophthalmoscope. Ophthalmic Surg Lasers Imaging 2003; 34: 49-52.

28 Yamaji H, Shiraga F, Tsuchida Y, Yamamoto Y, Ohtsuki H. Evaluation of arteriovenous crossing sheathotomy for branch retinal vein occlusion by fluorescein videoangiography and image analysis. Am J Ophthalmol 2004; 137: 834-841.

29 Horio N, Horiguchi M. Effect of arteriovenous sheathotomy on retinal blood flow and macular edema in patients with 
branch retinal vein occlusion. Am J Ophthalmol 2005; 139: 739-740.

30 Kube T, Feltgen N, Pache M, Herrmann J, Hansen LL. Angiographic findings in arteriovenous dissection (sheathotomy) for decompression of branch retinal vein occlusion. Graefes Arch Clin Exp Ophthalmol 2005; 243: 334-338.

31 Avunduk AM, Cetinkaya K, Kapicioglu Z, Kaya C. The effect of posterior vitreous detachment on the prognosis of branch retinal vein occlusion. Acta Ophthalmol Scand 1997; 75: 441-442.

32 Pe'er J, Folberg R, Itin A, Gnessin H, Hemo I, Keshet E. Vascular endothelial growth factor up regulation in human central retinal vein occlusion. Ophthalmology 1998; 105: 412-416.

33 Stefansson E, Novack RL, Hatchell DL. Vitrectomy prevents retinal hypoxia in branch retinal vein occlusion. Invest Ophthalmol Vis Sci 1990; 31: 284-289.
34 Kuhn F, Kiss G, Mester V, Szijarto Z, Kovacz B. Vitrectomy with internal limiting membrane removal for clinically significant macular edema. Graefes Arch Clin Exp Ophthalmol 2004; 242: 402-408.

35 Avci R, Kaderli B, Avci B, Simsek S, Baykara M, Kahveci Z et al. Pars plana vitrectomy and removal of the internal limiting membrane in the treatment of chronic macular oedema. Graefes Arch Clin Exp Ophthalmol 2004; 242: 845852.

36 Rosenblatt BJ, Shah GK, Sharma S, Bakal J. Pars plana vitrectomy with internal limiting membranectomy for refractory diabetic macular edema without a taut posterior hyaloid. Graefes Arch Clin Exp Ophthalmol 2005; 243: 20-25.

37 Mandelcorn MS, Nrusimhadevara RK. Internal limiting membrane peeling for decompression of macular edema in retinal vein occlusion: a report of 14 cases. Retina 2004; 24: 348-355. 